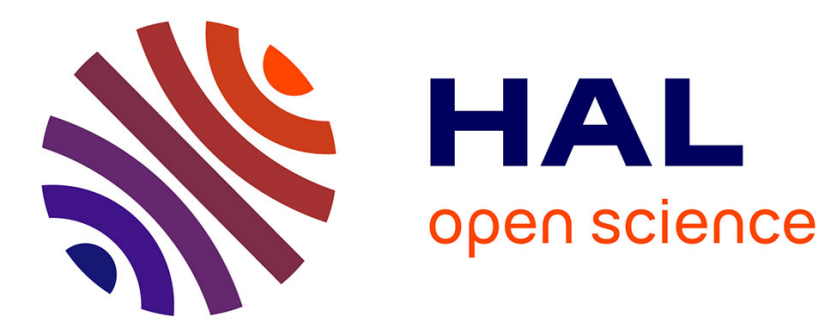

\title{
Microlithography with a laser plasma X-ray source
}

\author{
I. Thoubans, R. Fabbro, H. Pepin, M. Chaker
}

\section{To cite this version:}

I. Thoubans, R. Fabbro, H. Pepin, M. Chaker. Microlithography with a laser plasma X-ray source. Revue de Physique Appliquée, 1989, 24 (10), pp.1001-1006. 10.1051/rphysap:0198900240100100100 . jpa-00246132

\section{HAL Id: jpa-00246132 https://hal.science/jpa-00246132}

Submitted on 1 Jan 1989

HAL is a multi-disciplinary open access archive for the deposit and dissemination of scientific research documents, whether they are published or not. The documents may come from teaching and research institutions in France or abroad, or from public or private research centers.
L'archive ouverte pluridisciplinaire $\mathbf{H A L}$, est destinée au dépôt et à la diffusion de documents scientifiques de niveau recherche, publiés ou non, émanant des établissements d'enseignement et de recherche français ou étrangers, des laboratoires publics ou privés. 


\title{
Microlithography with a laser plasma X-ray source
}

\author{
I. Thoubans ( $\left.{ }^{1}\right)$, R. Fabbro $\left({ }^{1}\right)$, H. Pepin $\left(^{2}\right)$ and M. Chaker $\left(^{2}\right)$ \\ (1) Laboratoire LULI, Ecole polytechnique, 91128 Palaiseau Cedex, France \\ (2) INRS Energie Université du Québec P. O. Box 1020, Varennes, Québec, Canada JOL 2PO
}

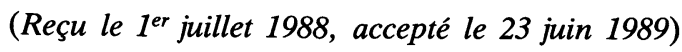

\begin{abstract}
Résumé. - Dans ce papier, nous présentons les résultats obtenus concernant une source $\mathrm{X}$ créée par plasma laser et, en particulier, l'influence de la longueur d'onde laser, de la durée et de la forme de l'impulsion sur le rendement de conversion ont été étudiées. Cette source a ensuite été utilisée pour la reproduction de motifs submicroniques en utilisant comme résine la FBM120. Les résultats expérimentaux sont comparés aux résultats des simulations numériques obtenus avec notre code LITHOX.
\end{abstract}

\begin{abstract}
In this paper, we present our results about a laser produced X-ray source and in particular we have been interested in the influence of laser wavelength, pulse duration and pulse shape on conversion efficiency. Then, we have used this source in order to reproduce submicron pattern using the FBM120 resist which have been characterized. Experimental results are compared with numerical results obtained with our code LITHOX.
\end{abstract}

\section{Introduction.}

Optical lithography is limited in the production of submicron devices by diffraction. So X-ray lithography represents a promising approach for both high resolution $(0.1-0.5 \mu \mathrm{m})$ and high throughput lithography processes. Different X-ray sources can be used : X-ray tubes $[1,2]$, synchrotron radiation $[3$, 4], plasma sources generated by either electrical discharges $[5,6]$ or laser beams $[7,8]$. X-ray tubes are a well known technique, quite inexpensive but have a low brightness and a large size leading to an important blurring effect. Sources using synchrotron radiation are very bright and emit a highly collimated radiation. They are well suited for very large volume production but are too expensive for small and moderate size production facilities. An alternative source is needed which could be the plasma source where the $\mathrm{X}$-ray radiation is emitted by a hot plasma. We present here different results about a laser created plasma source and the diagnostics which have been used to study the different parameters (in particular the influence of the pulse duration and the shape of the pulse, the influence of the laser wavelength and also the role of the target with which we create the plasma). Then we show an application of such a source for lithography. A simulation program allows us to determine the laser conditions which maximise the energy deposited in the resist as well as the best geometrical conditions. Finally we present some experimental results on sensitivity and patternability of FBM120 resist.

\section{Experimental setup and diagnostics.}

These experiments have been realised with the Ndglass laser of the LULI Laboratory. To create the plasma, the laser beam is focused on a metallic target. The experimental setup is given in figure 1 . To record the X-ray signal we use both an X-ray multichannel (described in details in Ref. [9]) composed by an array of 7 XRD and 2 PIN diodes equipped with appropriate filters, and a transmission grating spectrometer.

From the signal recorded by the different diodes we determine the emission spectrum via an iterative procedure where a trial spectrum is folded with the filters and detectors response and compared with the experimental spectrum. A new spectrum is then generated. We assume that the result is correct when the difference between the two is less than $10 \%$ for each channel. We can compare this result with the spectrum given by the transmission grating spec- 


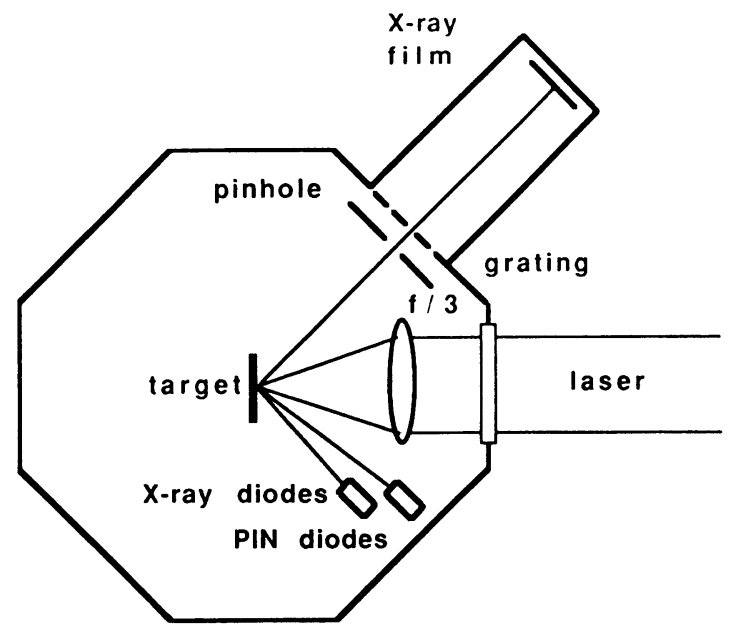

Fig. 1. - Experimental setup.

trometer which consists of free standing parallel gold bars. We use two types of gratings : 1000 lines per $\mathrm{mm}$ and 2000 lines per $\mathrm{mm}$. The X-ray emission is recorded using an absolutely calibrated X-ray film, Kodack 101-01 [10, 11]. After densitometry, the film is unfolded via an iterative procedure where we have taken into account the six first order. Two aspects have to be taken in consideration: diffraction and geometrical effects. Since $\lambda \leqslant 200 \AA$, geometrical effects are the most important (except for very small sources and pinholes with very small diameter). Then the spectral resolution is given by:

$$
\Delta \lambda=\frac{a p R}{r(R-r)}+\frac{a d}{r}
$$

where $d$ is the source diameter, $a$ the grating period, $p$ the pinhole diameter, $R$ the source-film distance and $r$ the source-pinhole distance. Using a transmission grating spectrometer we get a good spectral resolution (4 $\AA$ with our experimental conditions) and a good spatial resolution. The different experimental spectra which are obtained with the X-ray multichannel or the grating spectrometer can be compared with the simulated spectra given by our code XSOURCE [12].

\section{Characteristics of the $\mathrm{X}$-ray source.}

2.1 X-RAY SPECTRUM. - As shown in previous publication [8] spectra emitted by laser created Xray source are relatively broad $(0.1 \leqslant h \nu \leqslant 5 \mathrm{keV})$ and the X-ray emission is adjustable in photon energy by a convenient choice of target atomic number and irradiation conditions. As one can see in figure 2, the hard radiation falls rapidly for $h \nu \geqslant 2 \mathrm{keV}$. This is an advantage since for $h \nu \geqslant 3 \mathrm{keV}$ production in the resist of electrons with a large scattering range affects the quality of resolution.

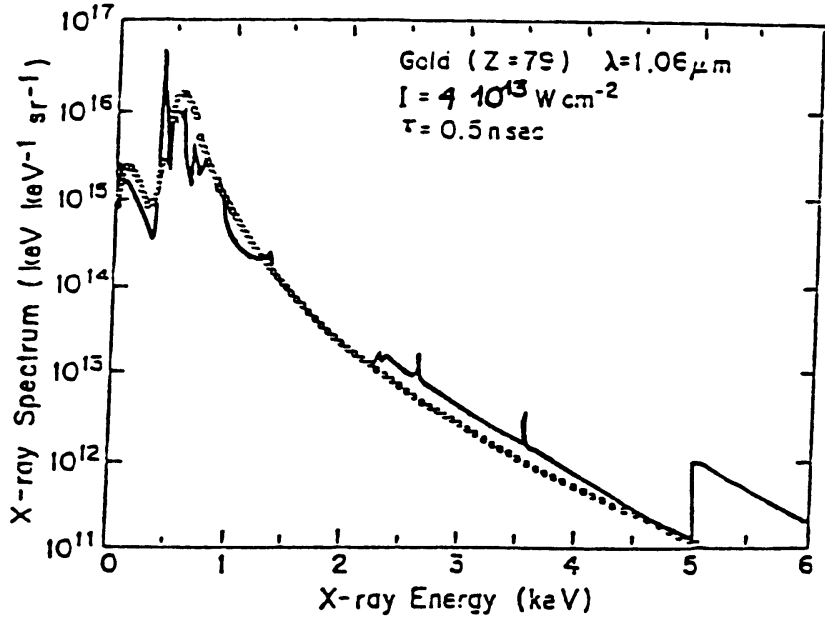

Fig. 2. - Experimental (O০O) and theoretical (-) spectra of $\mathrm{Au}\left(1.06 \mu \mathrm{m}, I=4 \times 10^{13} \mathrm{~W} / \mathrm{cm}^{2}\right)$.

2.2 X-RAY CONVERSION VERSUS INTENSITY. INFLUENCE OF WAVELENGTH. - At $1.06 \mu \mathrm{m}$ with a pulse duration of $0.6 \mathrm{~ns}, \mathrm{X}$-ray conversion efficiency of the laser plasma source is excellent. With copper target we can reach about $8 \%$ for $\mathrm{keV}$ radiation with laser intensity greater than $5 \times 10^{12} \mathrm{~W} / \mathrm{cm}^{2}$ (Fig. 3). If we

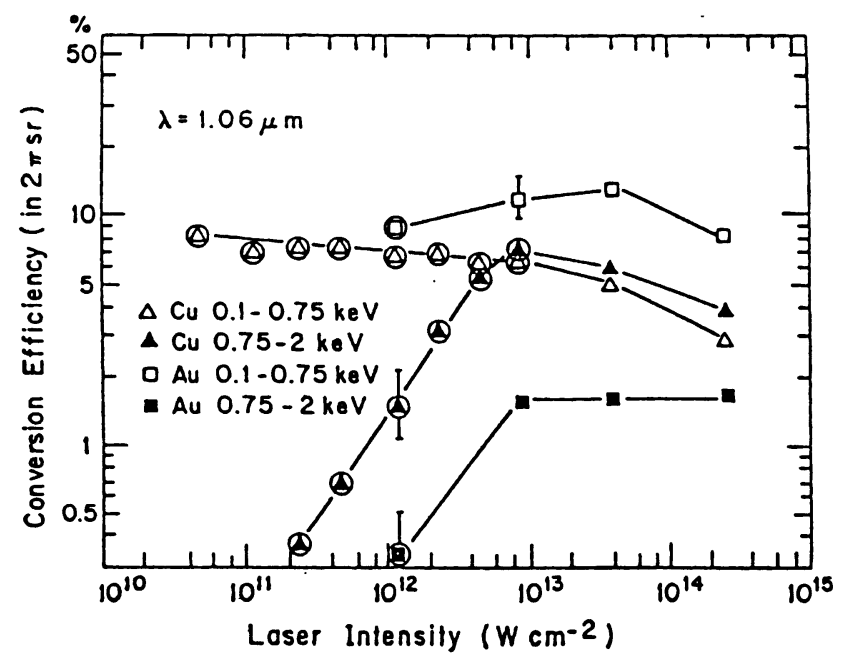

Fig. 3. - Conversion efficiency at $1.06 \mu \mathrm{m}$ (circled data points have been obtained with large focal spot).

operate at the $1.06 \mu \mathrm{m}$ harmonics (by doubling or quadrupling frequency), the X-ray conversion efficiency is improved (Fig. 4). But it is calculated with respect to the laser energy which reaches the target. So we have to take into account the energy loss in the crystals used for frequency multiplication. So there is no special advantage to work at $0.26 \mu \mathrm{m}$ with a Nd-glass laser. The threshold which appear for $I \leqslant 5 \times 10^{12} \mathrm{~W} / \mathrm{cm}^{2}$ is due to a rapid decrease of the $\mathrm{keV}$ emissivity with temperature. 


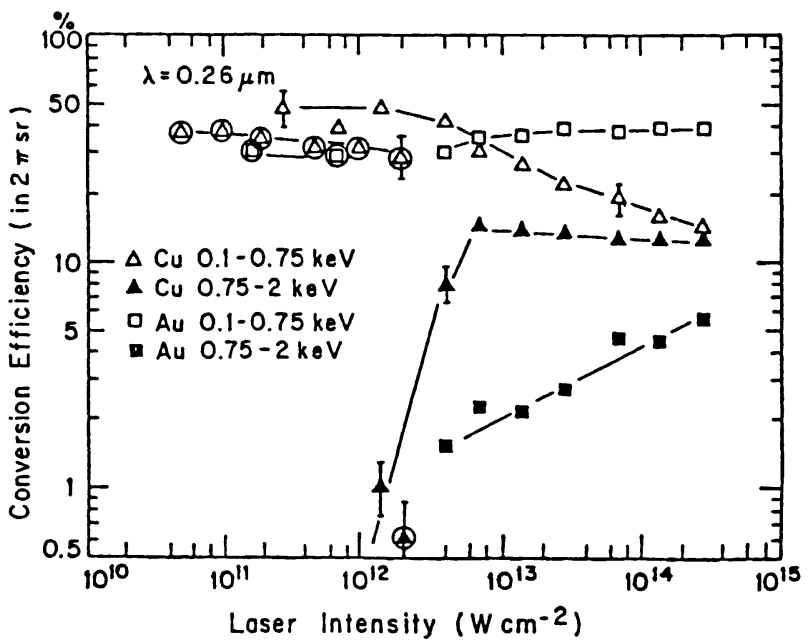

Fig. 4. - Conversion efficiency at $0.26 \mu \mathrm{m}$ (circled data points have been obtained with large focal spot).

On the other hand with $\mathrm{KrF}$ lasers a $3 \% / \mathrm{sr}$ overall conversion efficiency is attainable due to the advantage of using directly the UV radiation $(0.249 \mu \mathrm{m})$. However the additional requirement on laser intensity $\left(I=10^{13} \mathrm{~W} / \mathrm{cm}^{2}\right)$ imposes that a special effort has to be made on the appropriate $\mathrm{KrF}$ laser.

2.3 INFLUENCE OF PULSE DURATION. INFLUENCE OF A PREPULSE. - We have also studied the influence of the pulse duration on $\mathrm{keV} \mathrm{X}$-ray conversion. We use a copper target and the wavelength is $1.06 \mu \mathrm{m}$. Results are presented for 3 different pulses $(0.6 \mathrm{~ns}, 3 \mathrm{~ns}, 30 \mathrm{~ns})$. For different laser intensities (Fig. 5) the conversion efficiency is always greater for shorter pulses. For long pulses it seems that bidimensional effects become important. The plasma is not hot enough for a large $\mathrm{keV}$ emission. On an other hand the very short pulses $(\leqslant 200 \mathrm{ps})$ give a

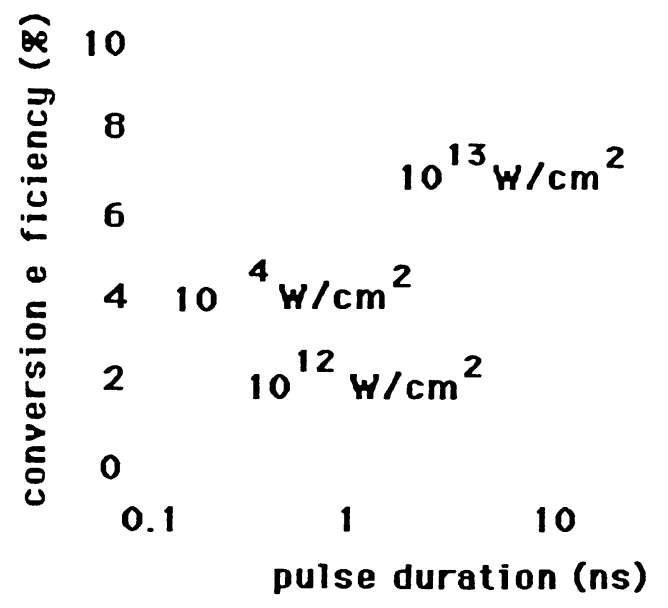

Fig. 5. - Influence of pulse duration on conversion efficiency for different laser intensities $(\lambda=1.06 \mu \mathrm{m}, \mathrm{Cu}$ target). lower X-ray emission than 600 ps pulse [13]. In this case the emission volume becomes too small.

When we use a prepulse (Fig. 6), the conversion efficiency increases when the prepulse rate increases. The same effect is observed with different focal spots. The increase is more important when the focal spot is bigger so it could be relied to the emission volume. The prepulse creates a pre-plasma which is heated more efficiently by the main pulse leading to a greater $\mathrm{keV}$ emission. These results have been obtained with both the X-ray multichannel and the grating spectrometer. A good agreement is observed between the two.

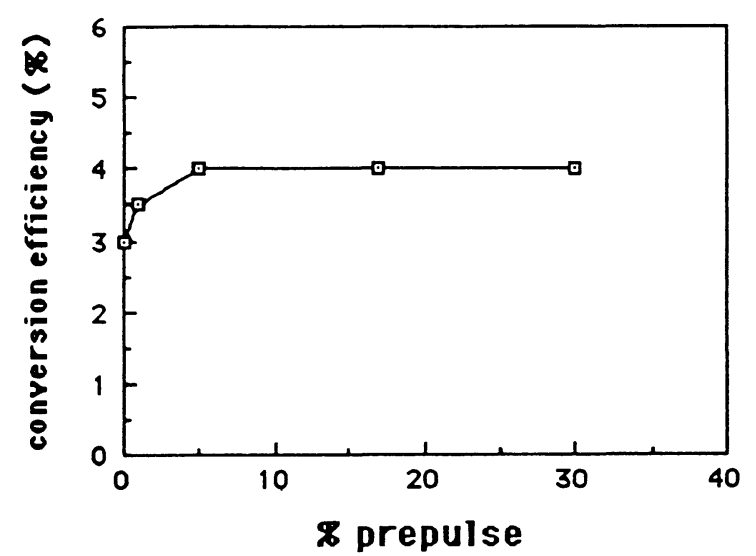

a)

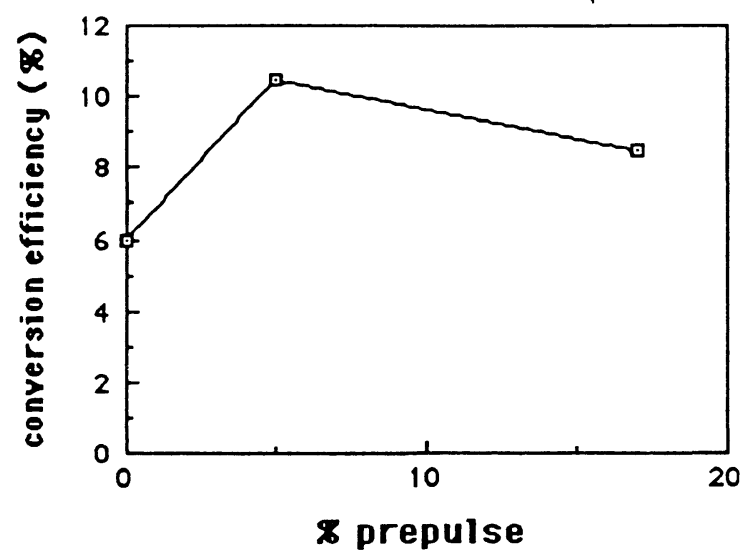

b)

Fi . 6. -

$I=4.5 \times 10^{13} \mathrm{~W} / \mathrm{cm}^{2} ; 6 \mathrm{~b}:$ focal spot $300 \mu \mathrm{m}, I=3 \times$ $\left.10^{13} \mathrm{~W} / \mathrm{cm}^{2}\right)$.

\section{X-ray lithography modeling and experiments.}

We want to optimize the X-ray lithography process with laser plasma sources. So we have developed a program which allows us to know the influence of the X-ray spectrum, the source to resist distance, the gap, knowing the resist parameters. 
3.1 Resist PARAMETERS. - First we have determine experimentally the sensibility curve of FBM120 resist. It is given in figure 7 . In order to determine

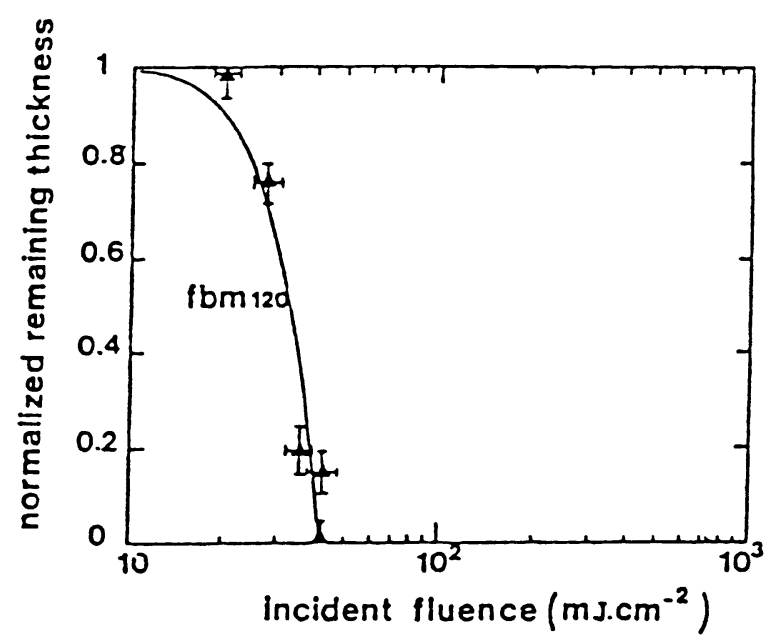

Fig. 7. - Theoretical and experimental normalized remaining thickness (NRT) of FBM120 as a function of Xray fluence.

the X-ray resist exposure curve and the parameters related to the etch rate modeling we first calculate the absorbed dose in the resist at a depth $z$ :

$$
\begin{aligned}
D(z)=\int_{0} S(h \nu) \mathrm{e}^{-\left(\alpha_{\mathrm{s}}(h \nu) \mathrm{I}\right)} \alpha_{\mathrm{r}}(h \nu) \times & \\
& \times \mathrm{e}^{-\left(\alpha_{\mathrm{r}}(h \nu) \mathrm{z}\right)} \mathrm{d}(h \nu)
\end{aligned}
$$

where $S(h \nu)$ is the X-ray intensity incident on the mask and $I$ the thickness of the mask substrate. $\alpha_{\mathrm{s}}$ and $\alpha_{\mathrm{r}}$ are respectively X-ray energy dependent absorption coefficients of the substrate and the resist. The development is simulated by using the curve fit of a etch rate versus dose curve described by Neureuther [14] :

$$
R(z)=R_{1} M^{\beta}\left(1+\frac{D(z)}{M D_{0}}\right)^{\beta}
$$

where $R(z)$ is the etch rate in $\AA / \mathrm{s}, R_{1} M^{\beta}$ the unexposed development rate constant in $\AA / \mathrm{s}, D$ the reference absorbed energy density in $\mathrm{J} / \mathrm{cm}^{3}, M$ a constant proportional to the initial average molecular weight $M_{\mathrm{n}}$ and $\beta$ is the asymptotic slope at very high dose. These resist parameters can be determined experimentally. For these purpose we have performed laser produced plasma exposure with $0.8 \mu \mathrm{m}$ FBM120 resist. A gold grid with $20 \mu \mathrm{m}$ features and $100 \mu \mathrm{m}$ spacing was used as a mask for sensitivity resist measurements. Height profiles of the grid pattern were obtained with a Dektak. A filter of $12 \mu \mathrm{m} \mathrm{Be}$ was used to select the $\mathrm{keV}$ radiation. FBM120 is developed during $90 \mathrm{~s}$ at $23{ }^{\circ} \mathrm{C}$ after exposure. Since we find experimentally that FBM120 unexposed development rate is very low $(\leqslant 1 \AA / \mathrm{s})$ a simple etch rate power low $R=\left(D / D_{0}\right)^{\beta}$ is more appropriate to fit the experimental resist exposure curve with $R$ in $\AA / \mathrm{s}$, $D_{0}=37 \mathrm{~J} / \mathrm{cm}^{3}$ and $\beta=4$.

3.2 Resist PRofiles Determination. - To define the $\mathrm{X}$-ray resist line edge profiles as a function of exposure, mask and resist properties, it is necessary to first determine the spatial distribution of the deposited X-ray radiation energy. The physical effect responsible for the intensity distribution on the resist surface is the Fresnel diffraction. For simulating the diffraction effect we will consider only one dimensional Fresnel calculation through an opaque X-ray mask from a broadband "point X-ray source ». The influence on diffraction patterns of a semi-trans-

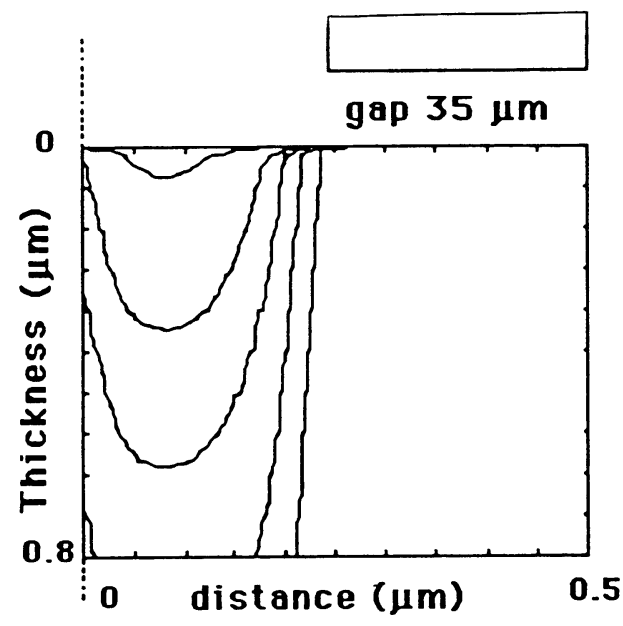

a)

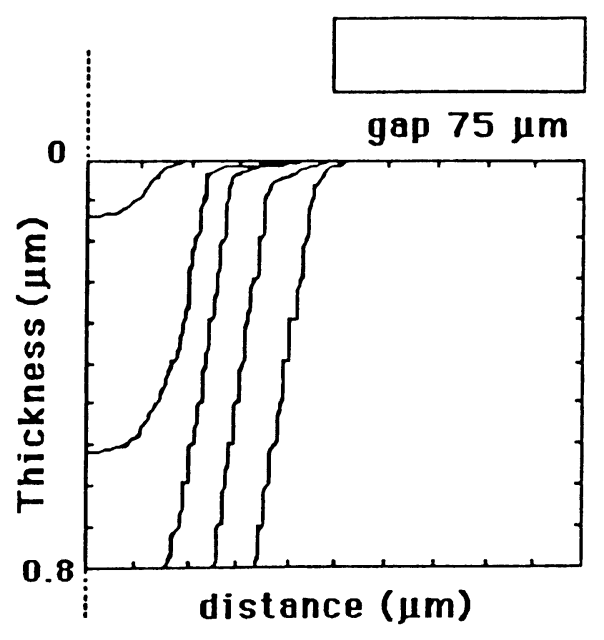

b)

Fig. 8. - FBM120 resist profiles obtained with a $0.5 \mu \mathrm{m}$ slit at two proximity gap $(35 \mu \mathrm{m}, 75 \mu \mathrm{m})$ and for different $\mathrm{X}$-ray fluences on resist $\left(50,40,30,25,15 \mathrm{~mJ} / \mathrm{cm}^{2}\right)$. 
parent X-ray mask, finite dimensions of the focal spot, a bevelled absorber edge and the mask absorber phase effects will be discussed elsewhere. We first calculate the field amplitude diffracted by a screen into an observation point from Fresnel-Kirchhoff integral. Following this an integration over the spectral distribution is done to determine the dose $D(x, z)$ absorbed in the resist at the coordinate $x$ and the depth $z$. The development package is based on an etching model in which the developer dissolves the resist off the surface without penetrating or swelling the film. A string model with adjustable segment number is used to calculate the progress of the etch front. At each development time step, the dissolution rate of the resist in contact with the developer is determined by etch parameters previously evaluated and the local absorbed dose. Figures 8 show the influence of the proximity gap on the computed resist profiles at different fluences on resist.

For FBM120 it is more appropriate to study the incident energy dependence of the resist profiles at a fixed development time (90 s) than the effect of varying development time. This is due to the fast variation of the FBM120 etch rate with the absorbed dose $(\beta=4)$. For fluences close to the resist sensitivity $\left(40 \mathrm{~mJ} / \mathrm{cm}^{2}\right)$ the resist profiles present steep walls and are quite identical for the two proximity gaps. For low fluences the shape of the curves are similar to the corresponding diffraction pattern. In figure 9 we show the influence of the slit

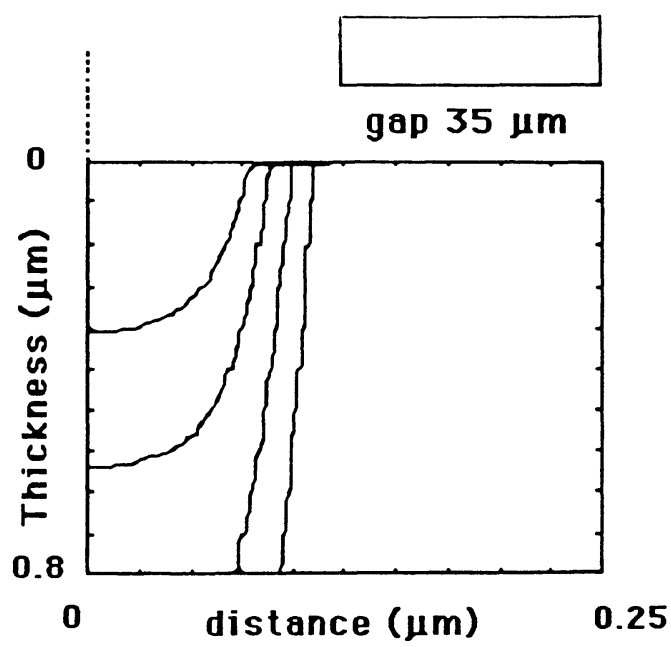

Fig. 9. - FBM 120 resist profiles obtained with a $0.25 \mu \mathrm{m}$ slit with a proximity gap of $35 \mu \mathrm{m}$, for different $\mathrm{X}$-ray fluences on resist $\left(50,40,30,25 \mathrm{~mJ} / \mathrm{cm}^{2}\right)$.

size with the same X-ray spectrum. In such conditions the energy deposition profile is not sharp along feature edges even with short gap.

So we see that a judicious choice of exposure and development conditions can attenuate the effect of diffraction in the proximity printing $\mathrm{X}$-ray lithography. Figure 10 shows an observed SEM profiles for $0.5 \mu \mathrm{m}$ features obtained using a transmission grating with $1000 \mathrm{l} / \mathrm{mm}$ as a mask. Lines are produced in $0.8 \mu \mathrm{m}$ thick resist with exposure conditions which are : copper target, $\lambda=1.06 \mu \mathrm{m}, \quad I=4 \times$ $10^{13} \mathrm{~W} / \mathrm{cm}^{2}$ and $\tau=3 \mathrm{~ns}$.

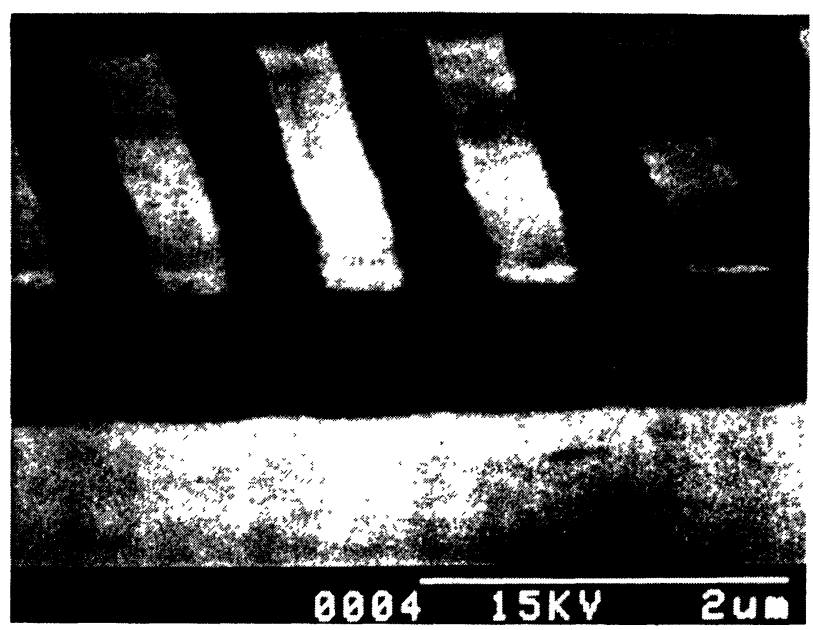

Fig. 10. - Observed SEM profile for $0.5 \mu \mathrm{m}$ lines in $0.8 \mu \mathrm{m}$ FBM120 resist with a proximity gap of $35 \mu \mathrm{m}$.

\section{Conclusion.}

Laser produced plasma have been investigated both theoretically and experimentally with respect to their suitability as X-ray lithography sources. It seems to be able to be the alternate source which is required for small and moderate size production facilities. The optimization of the laser parameters required for an industrial $\mathrm{X}$-ray lithography source is a problem which is not completely solved to date. We have seen that the laser intensity must be greater than $10^{13} \mathrm{~W} / \mathrm{cm}^{2}$ to have a good conversion efficiency in the $\mathrm{keV}$ range with a judicious choice of target atomic number. In these conditions the resist sensitivities are at least $10 \mathrm{~mJ} / \mathrm{cm}^{2}$. Realistic values of the source to mask distance $D$ and of the exposure time can e o aine $y$ consi ering a step an repeat lithography system and a given wafer throughput. Taking $D=20 \mathrm{~cm}$, a maximum step and repeat field size of $4 \times 4 \mathrm{~cm}^{2}$ and assuming a wafer throughput of 36-6 in. wafers/hour, the required average laser power satisfies the following relation :

$$
P \geqslant 4 F_{\mathrm{R}}\left(\mathrm{mJ} / \mathrm{cm}^{2}\right) \quad F_{\mathrm{R}}=\text { resist sensitivity } .
$$

Assuming a minimum $100 \mu \mathrm{m}$ focal spot diameter, the laser pulse must fulfil :

$$
\tau_{\mathrm{p}}(\mathrm{ns}) \leqslant E_{\mathrm{L}}(\mathrm{J})
$$


to have $I \geqslant 10^{13} \mathrm{~W} / \mathrm{cm}^{2}$. From these two relations we can determine the laser characteristics needed as an efficient X-ray lithography source taking the resist sensitivity as a parameter [8]. Using solid state lasers a minimum of $100 \mathrm{~W}$ average power is required if we assume a resist sensitivity of $25 \mathrm{~mJ} / \mathrm{cm}^{2}$. A laser having a low energy output per pulse (i.e. $1 \mathrm{~J}$ ), a high repetition rate $(\geqslant 100 \mathrm{~Hz})$, a short pulse duration $(\approx 1 \mathrm{~ns})$ and a good beam quality to ensure a small focal spot should be a good candidate. This can be achieved with laser using slab geometries. The design of such lasers is in progress and should not present any difficulty given the present state of laser technology. The optimisation of the source ensure a high quality of the resist line edge profiles. Sub-half micron proximity printing necessitates a judicious choice of all the parameters involved in the exposure/development processes.

\section{References}

[1] Warlaumont J. M. and Maldonado J. R., J. Vac. Sci. Technol. 19 (1981) 1200.

[2] Fay B., Tay L., Alexander D., Proc. SPIE 537 (1985) 57.

[3] Neureuther A. R., Synchrotron Radiation Research, Eds. H. Winick and S. Doniach (Plenum Press New York) 1980, p. 223.

[4] Grobman W. D., Handbook of Synchrotron Radiation, Eds. E. E. Koch, Vol. 1 (1983) p. 1131.

[5] Pearlman J. S., Riordan J. C., Proc. SPIE 537 (1985) 102.

[6] Yoshihara H., Okada I., Saitoh Y. and Itabashi S., Proc. SPIE 632 (1986) 133.

[7] Nagel D. J., Whitlock R. R., Greig J. R., Pechacek R. E. and Peckerar M. C., Proc. SPIE 135 (1978) 46.

[8] Chaker M., Pepin H., Bareau V., Lafontaine B., Toubhans I., Fabbro R., Faral B., $J$. Appl. Phys. 63 (1988).
[9] Alaterre P., Pepin H., Fabbro R., Faral B., Phys. Rev. A 34 (1986) 4184.

[10] Кishimoto T., Absolute measurement of spectra emitted by laser produced plasmas, Internal report MPQ 108 (Dec. 1985).

[11] PAKula R., Generation of high temperature thermal radiation by laser heating of a cavity, Int. Rep. MPQ 95 (May 1985) 112-126.

[12] Pepin H., Alaterre P., Chaker M., Fabbro R., Faral B., Toubhans I., Nagel D. J., PeCKerar M. C., J. Vac. Sci. Technol. B 5 (1987) 27.

[13] Mochizuki T., Yamanaka C., Proc. SPIE 733 (1986).

[14] Neurether A. R., J. Vac. Sci. Technol. 15 (1978) 1004. 